\title{
Strengthened appraisal
}

\author{
Christiane Shrimpton, MCROphth
}

\section{BACKGROUND}

Regular appraisal has been with us for several years now and there has been talk of the introduction of revalidation for a while, too. Sometimes it may feel like the former is just a tick box exercise and the latter will never get here. I would like to challenge you to use the current focus on strengthening appraisal as an opportunity to look at the way appraisals are currently conducted and make the most of this process. This can not only make it more satisfying now, it will also help to be better prepared for revalidation when it finally gets introduced next year.

Appraisals are used in many professions to review the performance of an employee over the preceding year and set professional development goals for the following year. Medical appraisal was introduced as a supportive and developmental process to allow doctors to review their current practice and consider and review their plans for continuing professional development annually. The aim of the process is an improvement in professional practice. Medical appraisal is not designed to identify poor performance and this will not be part of its role in strengthened appraisal either. Instead more emphasis will be placed on the quality of the supporting evidence provided for the appraisal discussion. It will also seek to improve the standard of the appraisal process.

\section{APPRAISAL AND REVALIDATION}

'Supporting information for appraisal and revalidation' gives guidance on the kind of information that should be provided for the appraisal. ${ }^{(3)}$ Over the five-year revalidation cycle this needs to include six types of information:

I. Continuing professional development

2. Quality improvement activity

3. Significant events

4. Feedback from colleagues

5. Feedback from patients (where applicable)

6. Review of complaints and compliments
The General Medical Council recently published a framework for appraisal and revalidation. ${ }^{(1)}$ Doctors should use this to reflect on their practice, reflect on the supporting information they have gathered and what that demonstrates about their practice, help them identify areas where they can make improvements and develop further and use it to demonstrate their practice is up to date. The process is mapped to four domains:
Knowledge, skills and performance
2. Safety and quality
3. Communication, partnership and teamwork
4. Maintaining trust

Three attributes define the scope and purpose of each domain. These are based on 'Good Medical Practice'.(2) All roles a doctor is working in should be included in appraisal. Apart from the clinical element of the job this may be educational commitments like clinical and educational supervision or lead positions like audit lead or clinical lead. The document

\section{THE APPRAISAL PROCESS}

Medical staff at University Hospitals of Morecambe Bay NHS Foundation Trust (UHMBFT) have had annual appraisals for several years now. These are currently performed by the relevant associate medical director, clinical lead or other colleague. The trust has provided some training sessions for appraisers, others have had training elsewhere. In addition to local appraisals some staff also appraise people externally. The responsible officer for appraisal at the trust is Peter Dyer, the Medical Director. He also receives training for this role.

In order to assess the quality of the current appraisal process we asked consultants and staff grade and associate specialist doctors to complete a short survey. This included questions about the appraisal discussion, the appraiser and the support from the organisation. We received 45 replies, a response rate of $20 \%$. The time taken for the appraisal discussion was 30 
minutes in $35.6 \%$ and 60 minutes in $46.7 \%$ of respondents. A summary of the responses is available in figure 1.

In addition to the nine questions above we also invited free text comments in all three areas. Several themes emerged. Many respondents had difficulty accessing useful information for their appraisal. There was a perception that appraisal is just something that needs to be done without any real benefit. There were also several requests for more and better-trained appraisers. Several respondents felt there was little support at trust level for appraisal and some thought UHMBFT should fund access to the NHS appraisal toolkit in the future. This information shows that there is scope for improving our process locally.

So what are we currently doing? As part of a project to improve the quality of appraisals at UHMBFT we are working on several areas. These include:

I. Introduction of an appraisal process for lead educators

2. Setting up a database of current appraisers

3. Introducing a job description with clear roles responsibilities for appraisers

4. Ensuring initial training and ongoing support for all appraisers

5. Developing local training for appraisers and appraisees

6. Improving the quality of information available to appraisees

Look out for more information about this in the coming months.

\section{REFERENCES}

I. General Medical Council. The Good Medical Practice Framework for appraisal and revalidation. 201 I

Available from:

http://www.gmc-uk.org/GMP_framework_2_.pdf_39974670.pdf

2. General Medical Council. Good Medical Practice. 2006, updated March 2009

Available from:

http://www.gmc-uk.org/static/documents/content/GMP_0910.pdf

3. General Medical Council. Supporting information for appraisal and revalidation, 201 I

Available from:

http://www.gmc-uk.org/Supporting_information_2_.pdf_39974163.pdf

\section{Research in Morecambe Bay is recognised at international meetings}

University Hospitals of Morecambe Bay NHS Foundation Trust student and junior doctor researchers have had a wave of success with 14 research papers accepted as poster presentations at the international Rheumatology Meeting held in London in May 2011 . We have also had two pieces of research accepted as talks, and a prestigious travel bursary awarded to intercalating student Alex Oldroyd for that meeting.
This adds to a research paper being accepted at the American Thoracic Meeting later this year, and the Medical Student Prize being awarded for an unprecedented second time to Alex Oldroyd by the British Society for Rheumatology for Research, to be presented at the forthcoming British Society Meeting.

Marwan Bukhari

Rheumatology Department, Royal Lancaster Infirmary 